\title{
Assessing demographic differences in decisional balance for smoking prevention and temptations to try smoking among adolescent subgroups
}

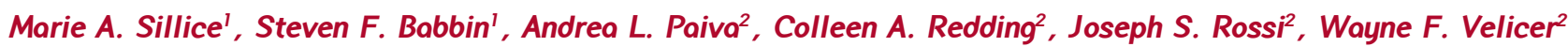

\begin{abstract}
INTRODUCTION Cigarette smoking initiation remains prevalent in adolescence. Effective prevention methods are needed to dissuade this behavior. Demographic factors are identified as important risk factors in the developmental nature of smoking in adolescence. The current study investigates potential demographic differences for two new trans-theoretical model measures, the Decisional Balance Inventory (pros and cons) for Smoking Prevention and the Temptations to Try Smoking Scale.

METHODs A sample of 6th grade Rhode Island students from 20 middle schools $(\mathrm{N}=4151)$ who were participating in a longitudinal and computer-delivered intervention for substance abuse prevention was assessed on these measures at baseline. Three MANOVA tests were conducted to assess the impact of race (White vs. Non-White), ethnicity (Hispanic vs. Non-Hispanic) and gender (male vs female).

RESULTS Significant effects for race and ethnicity were found for Decisional Balance and Temptations to Try Smoking. For race, Whites reported lesser pros $(\mathrm{p}<.0001)$ and Non-Whites reported higher cons $(\mathrm{p}<.0001)$ and temptations to try smoking $(\mathrm{p}<.0001)$. Differences for ethnicity showed that Hispanics were higher on pros $(\mathrm{p}<.0001)$ and temptations to try smoking $(p<.0001)$ than Non-Hispanics. Non-Hispanics reported higher cons $(p<.0001)$. Gender differences were noted only for temptations to try smoking, and showed females were higher on this construct than males $(\mathrm{p}<.0001)$. The effect sizes were .01 or below.

ConcLusions The results did not demonstrate a strong association between these demographics and constructs, suggesting that tailored prevention methods based solely on these factors may not dissuade smoking in this group.
\end{abstract}

\author{
AFFILIATION \\ 1 Department of Psychiatry and \\ Human Behavior, Alpert Medical \\ School, Brown University, Centers \\ for Behavioral and Preventive \\ Medicine, The Miriam Hospital, \\ Providence, United States \\ 2 Cancer Prevention Research \\ Center and Department of \\ Psychology, University of Rhode \\ Island, Kingston, United States

\section{CORRESPONDENCE TO} \\ Marie A. Sillice. Department of \\ Psychiatry and Human Behavior \\ Alpert Medical School, Brown \\ University, Centers for Behavioral \\ and Preventive Medicine, The \\ Miriam Hospital, 164 Summit \\ Street, 02906 Providence, United \\ States. Email: marie_sillice@ \\ brown.edu
}

\section{KEYWORDS}

Smoking initiation, demographic factors, adolescents, transtheoretical model, effect size estimation

Received: 5 August 2016

Revised: 10 April 2017

Accepted: 19 April 2017

\section{INTRODUCTION}

The 2014 Surgeon General Report shows that approximately 600,000 middle school students smoke cigarettes ${ }^{1}$. National data on smoking trends among adolescents show the average age for smoking initiation to be 16 years old ${ }^{2}$. However, a number of studies have shown that adolescents start smoking as early as age 12 or $13^{1-5}$. Early smoking initiation has shown to be a strong risk factor for becoming a regular smoker as well as the trajectory of dependence in adulthood ${ }^{1,6-8}$. The adverse health effects associated with cigarette smoking include stroke, lung cancer, heart disease and premature death, ${ }^{1,2}$ thus demonstrating the ongoing need for effective prevention programs to dissuade this behavior in this group. Determining important risks factors associated with adolescent cigarette smoking initiation is a priority, given its implication in informing prevention methods among adolescents.

Demographic Factors and Cigarette Smoking Initiation Numerous studies have identified race, ethnicity and gender as risk factors in adolescent smoking initiation ${ }^{1-13}$. However, these 
studies continue to produce mixed results. National data from the 2014 Surgeon General Report found that White adolescents had a higher prevalence of smoking initiation (between ages of 12-17) than Black and Hispanic adolescents. Conversely, other studies have found that Hispanic adolescents were more likely to start smoking at an early age compared to their White and Black counterparts $^{6,7}$. Additionally, Hispanic adolescents were noted to have higher progression rate from initial to daily smoking in comparison to White and Black adolescents ${ }^{6}$. A 2013 CDC report found that Hispanic and White adolescents had similar rates for smoking initiation ${ }^{5}$. Similarly to race and ethnicity, the role of gender in smoking initiation in adolescence has produced inconclusive results ${ }^{1,10,14,15}$. A number of studies have identified being male as a risk factor for smoking initiation ${ }^{10,14,15}$ while other studies have found that being female was associated with higher prevalence for this behavior ${ }^{2,4}$. The 2014 Surgeon General Report found no gender differences in adolescent cigarette smoking initiation ${ }^{1}$.

\section{Addressing the Inconsistencies}

The inconsistencies between research studies of risk factors associated with adolescent smoking initiation are problematic for the development of effective prevention approaches ${ }^{16-18}$. The effectiveness of prevention programs rests primarily on the inclusion of important risk factors related to the target behavior ${ }^{16-18}$.It must be determined whether or not demographic variables play important roles in adolescent smoking initiation. Research studies on adolescent smoking initiation have traditionally used statistical hypothesis testing as the singular methodological approach for determining risks ${ }^{16,18}$. Further, the use of inadequate instruments in studies that assess cognitions and behaviors related to cigarette smoking in adolescence is likely introducing discrepancies in the knowledge of important correlates of cigarette smoking initiation in this group ${ }^{16,17}$.

Statistical hypothesis testing has been criticized for nearly three decades, with many researchers asking for its eradication in the social sciences ${ }^{19-22}$. This statistical inference method is used to determine whether or not an effect exists between a set of variables based on an alpha cut-off value (e.g. p < $.05)^{9-22}$. However, alpha is highly influenced by large samples and likely to produce significant differences between variables, even if such differences are negligible ${ }^{21,22}$. Moreover, significant testing does not provide information on the size of the effect, therefore obfuscating the knowledge of the practical significance between the variables ${ }^{22}$. Research studies on risk factors associated with cigarette smoking initiation in adolescence consist of large samples of participants ${ }^{1-7}$ and demonstrate the central importance of using effect sizes (in addition to hypothesis significant testing) to identify influential factors that are associated with this behavior for this group. An effect value size provides information about the magnitude of the association between variables by quantifying the proportion of variance accounted for by the factor relative to the dependent construct(s $)^{20,21}$. Effect size taxonomy has been recommended for various analytic method $\mathrm{s}^{20}$. For example, the guidelines for reporting eta-squared values are: small effect size $=.01$, medium effect size $=.06$ and large effect size $=.14^{20}$. The larger the effect size, the stronger is the relationship between the variables ${ }^{20}$.

\section{Cigarette Smoking Initiation Construct}

Single item measures are prevalent in studies examining determinants in cigarette smoking initiation among adolescent subgroups. The complexities of behavior acquisition; such as cognitions and behaviors relevant to smoking onset, may not be adequately assessed using a single item measure ${ }^{16,17,23}$. Donovan's ${ }^{16}$ review of studies on substance initiation among adolescents noted the abovementioned problem as well as the lack of reporting on the psychometric properties of measures used in these studies. Another review conducted by Dar and Frenk $^{24}$ on studies on the initiation and progression of smoking among adolescents, noted similar concerns and recommended that researchers use empirically supported constructs of smoking initiation and report evidence of the validity and reliability of their instruments.

\section{Current Study}

The current study used the taxonomy of effects size in addition to significance testing to evaluate whether race, ethnicity and gender are strong risk factors for smoking initiation among adolescents using two empirically supported measures developed based on the Trans-theoretical Model (TTM) of behavior change, the Decisional Balance Inventory for Smoking Prevention (DBSPI $^{25}$ and the Temptations to Try Smoking Scale (TTSS) ${ }^{26}$. The TTM consists of multiple dimensions of behavior and behavior change, has been validated across numerous studies, and has been applied to many health risk behaviors including smoking ${ }^{27-30}$. The DBSPI measures an individual's assessment of the pros and cons (i.e. perceived benefits and perceived risks) of engaging in a behavior ${ }^{28,29,31}$. The TTSS is based on Bandura's Self-Efficacy mode ${ }^{32}$ and models of behavior maintenance ${ }^{33}$. This instrument assesses the degree to which an individual feels tempted to engage in a target behavior, as well as his or her confidence to abstain from this behavior, regardless of being in difficult or risky situations ${ }^{32,33}$. These measures have shown to be important mediator variables for various TTM-based health behavior interventions ${ }^{27-30}$. 


\section{METHODS}

\section{Participonts}

The sample consisted of 6 th grade students from 20 middle schools in Rhode Island who were involved in a TTM-tailored, computer-delivered substance use prevention program between 2007 and $2011^{34}$. Participants responded to single items and provided information about their race, ethnicity, gender and age. The total sample size was 4151. Participants with incomplete data were excluded from the analyses. The race and ethnicity variables were not mutually exclusive. Small numbers of participants identified themselves as being Hispanic and White, or Hispanic and Black. However, those samples were insufficient for analysis. The distribution of the sample allows for comparison between Whites $(\mathrm{n}=3388)$ and Non-Whites $(\mathrm{n}=336)$, and between Hispanics $(\mathrm{n}=625)$ and Non-Hispanics, $(\mathrm{n}=3389)$. The sample size for gender was 4082 (males, $\mathrm{n}=2125$, females, $\mathrm{n}=1957$ ). The mean age of participants was 11.40 ( $\mathrm{SD}=.70)$. Consent and other human subject protocols were approved by the University of Rhode Island Institutional Review Board, and research was conducted according to APA ethical guidelines.

\section{Measures}

Decisional Balance Inventory for Smoking Prevention (DBSPI). This scale consists of ten items, five representing the pros for smoking prevention (an example of an item is "kids who smoke have more friends") and five representing the cons for smoking prevention (an example of an item is "smoking makes people sick"). For each item, participants are asked to rate how much they "agree" or "disagree" on a 5-point Likert scale. The measure has strong psychometric properties and has been demonstrated to be invariant across different adolescent subgroup ${ }^{25}$. The Cronbach alphas for the cons scale and pros scale, respectively, were .77 and $.91^{25}$.

Temptations to Try Smoking Scale (TTSS). This measure consists of two correlated subscales, positive social (an example of an item for the positive social subscale is "when I want to be part of a crowd") and curiosity/stress, (an example of an item for the curiosity/ stress subscale is "when I want to know how a cigarette tastes" $)^{26}$. Each subscale consists of three items. Participants are asked to report how much they are tempted on a five-point Likert scale ranging from $1=$ "not at all tempted" to 5 "extremely tempted". The measure has strong psychometric properties and has been demonstrated to be invariant across different adolescent subgroups ${ }^{35}$. The Cronbach alpha coefficients for two subscales, respectively, are .87 and $.86^{26}$.

\section{Statistical analysis}

Three multivariate analysis of variance (MANOVA) tests were conducted to explore the relationships between three demographic variables (race, ethnicity and gender) and the pros, cons of smoking prevention and temptations to try smoking. Effects size of eta-square values and statistical significance values were used to assess whether or not these factors are important correlates for pros and cons for smoking prevention and temptations to try smoking in an adolescent sample. Bivariate correlation analysis was conducted to investigate multicollinearity between the dependent variables. The correlation values ranged from to .22 to .44 and thus showed no concerns for multicolinearity ${ }^{36}$.

\section{RESULTS}

Table 1 provides detailed multivariate results for the three demographic variables and the linear combinations of the dependent variables. Table 2 provides descriptive and inferential statistics for each subgroup.

Race. A significant multivariate effect for race was found ( $\mathrm{p}<$ $.0001)$. Univariate results for this relationship demonstrated a significant effect for the DBSPI; pros ( $\mathrm{p}<.0001)$, cons ( $\mathrm{p}<$ $.0001)$ and the TTSS $(p<.0001)$. White adolescents reported a higher mean score for the pros subscale $(\mathrm{p}<.0001)$ compared to Non-Whites. Conversely, Non-Whites reported higher cons to smoking initiation $(\mathrm{p}<.0001)$ as well as higher level of temptations to try smoking $(\mathrm{p}<.0001)$ than Whites. Partial etasquared values demonstrate a small association, respectively, between the pros subscale (np2 =.015) and temptations to try smoking (np2 =.012). A very small association was found between the race variable and cons subscale ( $\mathrm{np} 2=.006)$.

Ethnicity. A significant multivariate effect for ethnicity was found (.0001). Univariate results for this relationship demonstrated a significant effect for the DBSPI; pros $(\mathrm{p}<.0001)$ and cons $(p<.0001)$ and TTSS $(p<.0001)$. Hispanic adolescents

Table 1. Multivariate Results for the Decisional Balance and Temptations to Try Smoking ( $(\mathbf{=}=4151)$

$\begin{array}{lccccc} & \text { DF" } & \text { DF2 } & F & \lambda^{* *} & P \text {-value } \\ \begin{array}{l}\text { Race } \\ (n=3734)\end{array} & 3 & 3720 & 26.89 & .979 & <.000 \\ & & & & & \\ \begin{array}{l}\text { Ethnicity } \\ (n=2014)\end{array} & 3 & 4010 & 26.75 & .978 & <.000 \\ & & & & & \\ \begin{array}{l}\text { Gender } \\ (=4082)\end{array} & 3 & 4070 & 4.01 & .997 & <.0001\end{array}$

*Degrees of Freedom

** Wilks'Lamda 


\section{Research paper}

Table 2. Demographic Differences in Decisional Balance for Smoking Prevention and Temptations to Try Smoking among Adolescent Subgroups in Rhode Island US (n=4151) in 2007

\begin{tabular}{|c|c|c|c|c|c|c|}
\hline & $\left.\operatorname{Mean}(\mathrm{SD})^{*}\right)$ & $D F 1$ & $\mathrm{DF} 2$ & $F$ & P value & nрр $2 * *$ \\
\hline \multicolumn{7}{|l|}{ Pros Subscale } \\
\hline \multicolumn{7}{|l|}{ Race } \\
\hline Whites $(n=3388)$ & $6.68(2.87)$ & & & & & \\
\hline Non-Whites $(n=336)$ & $7.97(4.10$ & 1 & 3722 & 56.45 & $<.0001$ & .015 \\
\hline \multicolumn{7}{|l|}{ Ethnicity } \\
\hline Hispanics $(n=625)$ & $7.67(3.86)$ & & & & & \\
\hline Non-Hispanics $(n=3389)$ & $6.79(2.85)$ & 1 & 4012 & 56.20 & $<.0001$ & .014 \\
\hline \multicolumn{7}{|l|}{ Gender } \\
\hline Males $(n=2125)$ & $6.90(3.10)$ & & & & & \\
\hline Females $(n=957)$ & $6.75(2.95)$ & 1 & 4080 & 2.43 & .12 & .001 \\
\hline \multicolumn{7}{|l|}{ Cons Subscale } \\
\hline \multicolumn{7}{|l|}{ Race } \\
\hline Whites $(n=3388)$ & $22.17(4.70)$ & & & & & \\
\hline Non-Whites $(n=336)$ & $23.19(3.63)$ & 1 & 3722 & 22.68 & $<.0001$ & .006 \\
\hline \multicolumn{7}{|l|}{ Ethnicity } \\
\hline Hispanics $(n=625)$ & $22.14(4.70)$ & & & & & \\
\hline Non-Hispanics $(n=3389)$ & $23.13(3.70)$ & 1 & 4012 & 34.98 & $<.0001$ & .009 \\
\hline \multicolumn{7}{|l|}{ Gender } \\
\hline Males $(n=2125)$ & $22.91(4.02)$ & & & & & \\
\hline Females $(n=1957)$ & $23.09(3.70)$ & 1 & 4080 & 2.32 & .13 & .001 \\
\hline \multicolumn{7}{|c|}{ Temptations to Try Smoking } \\
\hline \multicolumn{7}{|l|}{ Race } \\
\hline Whites $(n=3388)$ & $7.11(3.15)$ & & & & & \\
\hline Non-Whites $(n=336)$ & $8.43(5.31)$ & 1 & 3722 & 46.28 & $<.0001$ & .012 \\
\hline \multicolumn{7}{|l|}{ Ethnicity } \\
\hline Hispanics $(n=336)$ & $8.14(5.07)$ & & & & & \\
\hline Non-Hispanics $(n=3388)$ & $7.02(3.12)$ & 1 & 4012 & 45.20 & $<.0001$ & .011 \\
\hline \multicolumn{7}{|l|}{ Gender } \\
\hline Males $(n=2125)$ & $7.06(3.08)$ & & & & & \\
\hline Females $(n=1957)$ & $7.43(3.84)$ & 1 & 4080 & 11.10 & $<.0001$ & .003 \\
\hline
\end{tabular}

*Standard Deviation

**Partial eta squared

had a higher mean score for pros to smoking initiation and temptations to try smoking than Non-Hispanics ( $p<.0001)$. Non-Hispanics reported more cons to smoking initiation than their Non-Hispanic counterparts $(\mathrm{p}<.0001)$. Similarly to race, a small effect size was noted between ethnicity, respectively, for the pros subscale (np2 =.014) and temptations to try smoking (np2 =.011). A very small association was found between ethnicity and the cons subscale (np2 =.006).

Gender. A significant multivariate effect for gender was found ( $\mathrm{p}$ $<.0001)$. Univariate results for this relationship demonstrated significant effect for the TTSS $(\mathrm{p}<.001)$. More women than men reported higher level of temptations to try smoking ( $\mathrm{p}$ $>$.0001). A very small association was found between gender and temptations to try smoking (np2 =.003). Statistically significant results were not noted for DBSPI, pros $(\mathrm{p}=.12)$ and cons $(\mathrm{p}=.13)$.

\section{DISCUSSION}

The results of the present study provide important information on the role of race, gender and ethnicity as important risk factors 
for smoking initiation in adolescence, using two empirically psychosocial constructs of smoking initiation in adolescence, the DBSPI and the TTSS. Statistical significant effects for race and ethnicity were noted for the DBSPI (pros and cons) and the TTSS. These results demonstrate that White adolescents had slightly lower pros toward engaging in cigarette smoking behaviors than Non-Whites. Non-White adolescents were more likely to report cons to cigarette smoking than their White counterparts. Additionally, more Non-Whites adolescents noted a higher level of temptations than Whites. Hispanic adolescents reported a higher mean score for both the pros subscale and the TTSS. Non-Hispanics endorsed more cons for cigarette smoking than Hispanics. Gender differences were noted only for the TTSS, and demonstrated that adolescent males had higher levels of temptations to try smoking compared to female adolescents.

However, the effect sizes for the three demographic variables and constructs were either in the small category of Cohen $d$ or below. Specifically, a small effect size was noted for race, respectively, between pros and temptations to try smoking and indicates a small association between each of the two demographic factors and the two constructs. Moreover, a partial $\mathrm{n} 2$ value of .006 between race and cons for smoking prevention subscale indicate that this factor accounts for less than $1 \%$ of variance within the measure. Similarly to race, a small effect size was noted between ethnicity, the pros subscale, and the TTSS. Further, a very small effect size was found for ethnicity and the cons subscale. Further, a very small effect size was demonstrated for the main effect of gender and the TTSS. Overall, these results suggest that these three demographic factors are not strongly associated with the DBSPI (pros and cons) and the TTSS. Accordingly, prevention methods tailored solely on these factors may not effectively prevent cigarette smoking initiation among these adolescent subgroups.

In contrast, the alpha values found for these studies were less than .0001 , demonstrating "very significant" evidence of demographic differences for the psychosocial constructs of smoking initiation among adolescents. Similarly to previous research studies on risk factors of smoking initiation in this population, the current study consists of a very large sample of participants. Interpretation of the effect size values of the results of the current study demonstrate overall a weak association between race, ethnicity, gender and the smoking initiation constructs.

The current study provides substantial insights and support for the need of effect size taxonomy in identifying and establishing important factors that influence smoking initiation in adolescence. The use of statistical significance testing as a single method or measure in determining risk factors has limited the development of knowledge in research of this area ${ }^{16,25}$.

The following limitations are noted. This study did not assess whether potential mediating variables may impact the relationship between the three demographic factors and the DBSPI (pros and cons) and the TTSS. It is possible that smoking related variables such as peer smoking or depression might be related to smoking initiation in these subgroups. A number of studies have cited a link between psychological risk factors (e.g. depressive symptoms) and cigarette smoking initiation in adolescence $^{37-40}$. Moreover, we did not investigate the association of the three demographic variables directly to cigarette smoking initiation. Further, the study included only adolescent subgroups that were of adequate sample size for analysis. Therefore, it is unclear whether similar findings would be noted with other ethnic and racial subgroups (e.g. Asian or African American adolescents). Finally, the current study did not explore any potential impact of the school environment and differences for the DBSPI (pros and cons) and the TTSS in this sample. Thus, future research with this population is encouraged to explore potential mediators associated with the relationship between these demographics and the two TTM constructs. Further, such studies should explore whether the school milieu plays a role in demographic differences for these constructs.

\section{CONCLUSIONS}

Notwithstanding the above limitations, the current study makes a substantial contribution to the understanding of the roles of race, ethnicity and gender in two measures of cigarette smoking initiation in adolescence. These results emphasize the importance of the assessment of effect size analyses (in additional to statistical testing) in the development, establishment of central risks factors in cigarette smoking initiation among adolescents, and help inform effective prevention strategies tailored for this group.

\section{REFERENCES}

1. Surgeon General Report-The Health Consequences of Smoking. 50 Years of Progress: A Report of the Surgeon General, 2014. Available at: http://www.surgeongeneral.gov/library/reports/50years-of-progress/full-report.pdf (accessed January 2016)

2. U.S. Department of Health and Human Services. Preventing Tobacco Use Among Youth and Young Adults: A Report of the Surgeon General. Atlanta, GA: U.S. Department of Health and Human Services, Centers for Disease Control and Prevention, National Center for Chronic Disease Prevention and Health Promotion, Office on Smoking and Health, 2012.

3. Singh T, Arrazola RA, Corey CG, et al. Tobacco use among middle and high school students - United States, 2011-2015. MMWR Morb Mortal Wkly Rep. 2016; 65:361-367. 
doi: http://dx.doi.org/10.15585/mmwr.mm6514a1

4. Fryar CD, Merino MC, Hirsch R, Porter KS. Smoking, alcohol use, and illicit drug use reported by adolescents aged 12-17 years: United States, 1999-2004 Natl Health Stat 2009 15, 1-28. Available at: http://www.cdc.gov/nchs/data/nhsr/nhsr015.pdf. (accessed May 2015)

5. Centers for Disease Control and Prevention. Tobacco product use among middle and high school students —United States, 2011 and 2012. MMWR Morb Mortal Wkly Rep. 2013; 62(45): 893-897.

6. Chen P, Jacobson KC. Developmental trajectories of substance use from early adolescence to young adulthood: gender and racial/ ethnic differences. J Adolesc Health. 2011; 50(2): 154-163. doi: $10.1016 /$ j.jadohealth.2011.05.013

7. Tucker JS, Ellison PL, Orlando M, et al. Substance use trajectories from early adolescence to adulthood. A comparison for smoking, binge drinking and marijuana use. J Drug Issues. 2005; 35(2): 307331.

8. White AR, Pendina R. Chen PH. Developmental trajectories of cigarette use from early adolescence into young adulthood. Drug Alcohol Depend. 2002; 65:167-178.

9. The 2004 Surgeon General's Report-The Health Consequences of Smoking. Available at: http://www.cdc.gov/tobacco/data_statistics/ sgr/2004/pdfs/chapter1.pdf. (accessed January 2016)

10. DuRant RH, Smith JA, Kreiter SR, Krowchuk DP. The relationship between early age of onset of initial substance use and engaging in multiple health risk behaviors among young adolescents. Am J Drug Alcohol Abuse. 2010; 36: 123-129.

11. Centers for Disease Control and Prevention. Fact sheet--CDC health disparities and inequalities report_US 2011. Available at: http:// www.cdc.gov/minorityhealth/reports/CHDIR11/FactSheet.pdf. (accessed March 2015)

12. Davis KC, Nonnemaker JM, Asfaw HA, Vallone DM. Racial/ethnic differences in perceived smoking prevalence: evidence from a national survey of teens. Int J Environ Res Public Health. 2010; 7, 4152-4168. doi: 10.3390/ijerph7124152.

13. Wallace JW, Vaughn MG, Bachman JG, et al. Race/ethnicity, socioeconomic factors, and smoking among early adolescent girls in the United States. Drug and Alcohol Depend. 2009; 104 (1): S42S49.

14. Kandel BD, Kiros GE, Schaffran C, Hu MC. Racial/ethnic differences in cigarette smoking initiation and progression to daily smoking: A multilevel analysis. Am J Public Health. 2004; 94(1), 128-135.

15. Mermestein R. Ethnicity, gender and risk factors for smoking initiation: An overview. Nicotine Tob Res. 1999; 1(2): S39-S43.

16. Donovan JC. Adolescent alcohol initiation: A review of psychosocial risk factors. J Adolesc Health. 2004; 3:529.e7-529.e18.

17. Brown AK, Moodie G, Hastings G, et al. The association of normative perceptions with adolescent smoking intentions. J Adolesc. 2010; 33: 603-614.

18. Garrett BE, Dube SR, Trosclair AT, Caraballo RS, Pechacek TF. Cigarette smoking- United States, 1965-2008. Centers for Disease Control and Prevention, MMWR Morb Mortal Wkly Rep. 2011; 60 (Suppl.): 109-113. Available at: http://www.cdc.gov/mmwr/pdf/ other/su6001.pdf (accessed May 2015)
19. Kline RB. Beyond Significance Testing: Reforming Data Analysis Methods in Behavioral Research.Washington, DC: American Psychological Association, 2004.

20. Cohen J. Statistical Power Analysis for the Behavioral Sciences, 2nd edition. Hillsdale, New Jersey: Lawrence Erlbaum Associates, 1988.

21. Cohen J. Quantitative method in psychology: A power primer. Psychol Bull. 1992; 112(1), 155-159.

22. DeVellis RF. Scale Development: Theory and Applications (Applied Social Research Methods Series, 26). London: Sage, 1991

23. Noar SM. The role of structural equation modeling in scale development. Struct Equ Modeling. 2003; 10(4): 622-647.

24. Dar R, Frenk H. Can one puff really make an adolescent addicted to nicotine? A critical review of the literature. Harm Reduct J. 2010; $7: 28$.

doi: 10.1186/1477-7517-7-28.

25. Kraemer HC, Stice E, Kazdin A, et al. How do risk factors work together? Mediators, moderators, and independent, overlapping, and proxy risk factors. Am J Psychiatr. 2001;15, 848-856. doi: 10.1176/appi.ajp.158.6.848

26. Plummer BA, Velicer WF, Redding CA, et al. Stage of change, decisional balance, and temptations for smoking: Measurement and validation in a large, school-based population of adolescents. Addict Behav. 2001; 26: 551-571.

27. Velicer WF, DiClemente CC, Prochaska JO, Brandenberg N. Decisional balance measure for assessing and predicting smoking status. J Pers Soc Psychol. 1985;48:1279-1289.

28. Plummer BA, Velicer WF, Redding CA, et al. Stage of change, decisional balance, and temptations for smoking: Measurement and validation in a large, school-based population of adolescents. Addict Behav. 2001; 26: 551-571.

29. Velicer WF, Diclemente CC, Rossi JS, Prochaska JO. Relapse situations and self-efficacy: An integrative model. Addict Behav. 1990; 15: 271-283.

30. Ding L, Pallonen U E, Velicer WF. Temptations to smoke and stages of change among adolescent smokers (Abstract). Ann Behav Med. 1995; 17: S087.

31. Hall KL, Rossi JS. (2008). Meta-analytic examination of the strong and weak principles across 48 health behaviors. Prev Med. 2008;46(3): 266-274.

doi: 10.1016/j.ypmed.2007.11.006

32. Bandura A. Self-efficacy mechanism in human agency. Am Psychol. 1982;37(2):122 147.

33. Velicer WF, Redding CA, Paiva AL, Mauriello, L.M., et al. Multiple behavior interventions to prevent substance abuse and increase energy balance behaviors in middle school students. Transl Behav Med: Practice, Policy and Research. 2013, 3:82-93. doi: 10.1007/s13142-013-0197-0

34. McGee H, Brick L, Babbin SF, et al. Psychometric assessment of the decisional balance inventory for smoking prevention in middle school students (Abstract). Ann Behav Med. 2012; 41: S213.

35. McGee HA, Babbin SF, Redding CA, et al. Prevention of smoking in middle school students: Psychometric assessment of the temptations to try smoking scale. Addict Behav. 2011; 37(4): 521-523. 10.1186/1479-5868-7-37.

36. Harlow LL. The Essence of Multivariate Thinking. Mahwah, New 


\section{Research paper}

Jersey: Lawrence Erlbraum Associates Publishers, 2005.

37. Asbridge M, Tanner J, Wortley S. Ethno-specific patterns of adolescent tobacco use and the mediating role of acculturation, peer smoking, and sibling smoking. Addiction. 2005; 100: 1340-1351. doi: 10.1111/j.1360-0443.2005.01165.x

38. Weiss JW, Mouttapa M, Cen S, et al. Longitudinal effects of hostility, depression, and bullying on adolescents smoking initiation. J Adolesc Health. 2010; 48 (6): 591-596.

doi: 10.1016/j.jadohealth.2010.09.012

39. Goodman E, Capitman J. Depressive symptoms and cigarette smoking among teens. Pediatrics. 2000; 106(4):748-758.

40. Substance abuse and mental health services administration (SAMHSA), HHS, results from the 2009 National Survey on Drug Use and Health, NSDUH: Volume I summary of national findings. Available at: http://www.oas.samhsa.gov/ NSDUH/2k9NSDUH/2k9ResultsP.pdf. (accessed on March 2015)

CONFLICT OF INTERESTS

The authors have

completed and submitted the ICMJE Form for

Disclosure of Potential

Conflicts of Interest and

none were reported.

\section{FUNDING}

This research was

supported in part by $\mathrm{NIH}$ Grants RO1CA119195

from the National Cancer Institute and G2ORR030883 from the National Center for Research Resources. While completing this paper, Dr. Marie A. Silllice was supported by NIH Grant T32 5T32HL076134-10 (NHLBI).

PROVENANCE AND PEER REVIEW

Not commissioned;

externally peer reviewed 